\title{
Early-stage venture capital in South Africa: Challenges and prospects
}

\author{
M. Jones \\ Investment Banking Division, Merrill Lynch South Africa, \\ morgan.jones@baml.com \\ C. Mlambo* \\ Graduate School of Business, University of Cape Town, \\ Private Bag, Rondebosch 7701, Republic of South Africa \\ chipo.mlambo@gsb.uct.ac.za
}

\begin{abstract}
The aim of this paper is to assess which factors impact the development of early-stage venture capital in South Africa. Factors identified for other markets and countries are explored and their relative importance in South Africa determined from the perspective of market participants. These include venture capital and private equity fund managers, government institutions, intermediaries and university research coordinators. The study used both an online survey, to capture a broad representation of opinion, and interviews, for in-depth responses. There was broad consensus among respondents with regards to the key factors requiring attention, which include the lack of funds targeted at early-stage investments, the lack of specialised fund managers, and the low entrepreneurial skillsets in the country. Through a detailed analysis of the responses, certain measures are proposed that can enhance the development of early-stage venture capital in South Africa such as engaging more with angel investors and improving the cooperation between the different market players in the sector.
\end{abstract}

*To whom all correspondence should be addressed.

\section{Introduction}

South Africa continues to focus on the need to drive local economic development and to encourage entrepreneurial activities especially among the 'previously disadvantaged populations" . Skillsets, training, regulation and bureaucracy play a pivotal role in entrepreneurial development. However, entrepreneurs often face increasing difficulties in accessing a broad range of financing options. Thus private equity (PE) and venture capital (VC) can be instrumental in filling this financing gap.

The difference between PE and VC is the form and stage at which the investments take place. Typically, PE refers to later stage investments through the acquisition and financing of established businesses. When financed by significant levels of debt, such transactions are known as leveraged buyouts (LBOs). These had become common in the developed PE markets of the US and Europe before the financial crisis. $\mathrm{VC}$, on the other hand, refers to a much earlier stage of financing of nascent businesses with limited or no track records, such as a new business idea. The aim is usually to finance their growth to significantly greater sizes in terms of market share and customer base. In either case, the aim is to make a profit on the initial investment by taking equity ownership in companies and holding the

\footnotetext{
${ }^{1}$ These are people of colour who were discriminated against during the Apartheid era.
}

investment for a specified period of time, often 3 to 5 years for $\mathrm{PE}$ funds and longer periods for $\mathrm{VC}$ funds.

The longer period of investment and the heightened risks posed by early-stage companies such as the unproven future demand of an undeveloped product, reaction by competitors (Kaplan et al., 2004) and the lack of entrepreneurial track record makes VC investment riskier than PE. Unlike PE, VC funding is highly unlikely to involve any form of debt financing due to the unattractive risk profiles of the funded firms. Thus the return on equity on VC investments is based on growth rather than on leverage. Early-stage VC investment is really the key in terms of spreading wider economic benefits because it takes place at the hurdle stage when so many new businesses face a funding gap. This is also the stage when university research can be capitalised upon and be developed further.

The significant role played by the VC market in innovation and in driving economic growth has been identified by a number of authors (Sahlman, 1990; Gilson, 2003; Kenney, Han \& Tanaka, 2002; Dossani \& Kenney, 2002). VC provides the necessary financing that enables businesses to bring ideas to market and expand (Lerner, Moore \& Shepherd, 2005). At the early-stage, businesses are unlikely to have tangible assets or revenue track records making them unattractive for typical bank financing (Gompers, 1995). Whereas many businesses are often started using personal savings and funding from friends and families, this 
form of financing is often not available in sufficient quantities to provide a realistic and sustainable form of financing for new developing businesses. An alternative source is 'angel' funding which, according to Sahlman (1990), may have outweighed VC funding as a source of finance in the US. However, inference may not be made to developing economies, which may well be without the prerequisite pool of angel investors. By definition, the pool of available resources from angels may not be viable for increasingly larger capital demands (Gompers, 1994).

VC funds add more value to investee companies by bringing their own expertise, networks of contacts, suppliers, financing expertise and key personnel (Dossani \& Kenney, 2002; and Jeng \& Wells, 2000). What is clear is that in the US, the birthplace of the VC industry and still the largest VC market in the world (Lerner et al., 2005), the VC industry has had some remarkable successes and has contributed to significant economic growth, job creation and wealth enhancement in that country (Sahlman, 1990). Companies that owe their current success to initial financing being made available by VC investors include Apple, Intel, Federal Express, Microsoft and Compaq (Sahlman, 1990). Of the many venture-capital-backed companies, about 579 went public during the 11 years ending in 1988 and their "total market value exceeded 30\% of the total market value of all comparable companies going public during that period" (Sahlman, 1990: 482).

VC-backed firms have not only been an important engine of economic growth and job creation, but they have also been responsible for commercialising cutting edge science such as biotechnology advancements and the internet (Gilson, 2003). Thus, according to the 2008 study by the South African Venture Capital \& Private Equity Association (SAVCA), VC plays a necessary and critical role in the innovation value chain. It makes it possible for new businesses to be established, leading to the creation of jobs and an increase in the country's export potential (SAVCA, 2008).

Despite its importance, early-stage VC funding is almost non-existent in South Africa. Companies such as HBD Ventures that have sought to enter the VC market subsequently withdrew to focus on PE. According to KPMG \& SAVCA (2009), no new early-stage funds were raised in South Africa through the VC market between 2004 and 2006 and the level has remained minimal in absolute terms. This is so despite R14.5 billion and R15.3 billion having been raised in South Africa for later stage investments in 2006 and 2007, respectively. In 2007, less than $1 \%$ of the amount raised was seed capital. As at 31 December 2008, the South African portfolio of seed, start-up and early-stage investments was $6 \%$ of the total unrealised portfolio at cost, which does not appear to be different from Europe's 9\% and is slightly more than half the $11 \%$ for the US (see Figure 1). However, early-stage financing is critical for South Africa given its social and developmental objectives.

\footnotetext{
2 This often represents High Net Worth Individuals (HNWI) investing directly into developing businesses.
}

Although the lack of early-stage financing is welldocumented in survey reports, research seeking practitioner or stakeholder input in determining the difficulties faced in successfully establishing and maintaining an active earlystage VC market in South Africa has been limited. Available research has focused, for example, on funding decision criteria used by VC firms (Van Deventer \& Mlambo, 2009), the potential of the South African VC market (Stillman, Sunderland, Heyl \& Swart, 1999) and its development in general (Lingelbach, Murray \& Gilbert, 2009).

This study seeks to fill this gap by examining if there are any specific characteristics that make the South African market uniquely difficult for early-stage VC to flourish. It also assesses if the role of government is well-developed and understood, for example, with regards to regulation, incentives and public-private partnerships. The measures proposed by respondents that can be taken to encourage and enhance VC as a source of funding to entrepreneurs in South Africa are also reported.

The paper proceeds as follows. Section 2 briefly reviews the literature on factors influencing the development and success of early-stage VC funding globally. Section 3 explains the data collection process and analysis. Section 4 presents the findings and Section 5 concludes and make some policy recommendations.

\section{Literature review}

According to the literature, there are a number of factors that impact early-stage VC development. These include the presence or absence of entrepreneurial skill sets, viable exit mechanisms, industry specialisations, monitoring problems, labour market rigidities, regulatory constraints, political distortions and the paucity of deal flow (Lingelbach et al., 2009).

\section{Entrepreneurs and skill sets}

The absence of the entrepreneurial spirit or culture can be an inhibitor to $\mathrm{VC}$ development. This has been the finding by Becker \& Hellman (2003) in the case of Germany. In addition, the lack of entrepreneurial skills was found to be the stumbling block to the emergence of entrepreneurial opportunities in the post-planned economies of Central and Eastern Europe (Karsai, Wright \& Filatotchev, 1997; Farag, Hommel, Witt \& Wright, 2004). The simple lack of quality ideas being presented to VCs contributes to the lack of development of the industry. Lerner et al. (2005) state that in New Zealand many of the interviewees complained about the quality of proposals they receive. In South Africa, where a sufficient level of opportunist entrepreneurs exist (Lingelbach et al., 2009), it is not clear if this translates to opportunities for VC. The situation is exacerbated by the unwillingness of entrepreneurs to cede control to "outsiders" (Karsai et al., 1997; Kenney et al., 2002; Banerjee, 2008). Many entrepreneurs would approach VC firms for debt financing instead of equity (Bliss, 1999), which shows that they simply do not understand the function of $\mathrm{VC}$. 


\section{Viable exit mechanisms}

The Venture Capital Cycle of Gompers \& Lerner (1999) has "successful exit from the investment" as a key component. Exits might involve, at a bare minimum, the potential for appropriate bankruptcy proceedings particularly for earlystage investors (Farag et al., 2004). Other exit mechanisms potentially suitable for $\mathrm{VC}$ investments include buy-backs by management, trade sales, initial public offerings (IPOs) and sell-on to other $\mathrm{VC} / \mathrm{PE}$ investors (Cumming et al., 2002). Where value maximising exit routes exist, providers of $\mathrm{VC}$ funding are able to invest with confidence knowing that if the investment develops successfully, a suitable return can be realised. Where entrepreneurs and managers are equity-compensated, a successful exit would encourage effort on their part and provide them with an incentive to align their objectives with those of the VC (Jeng et al., 2000).

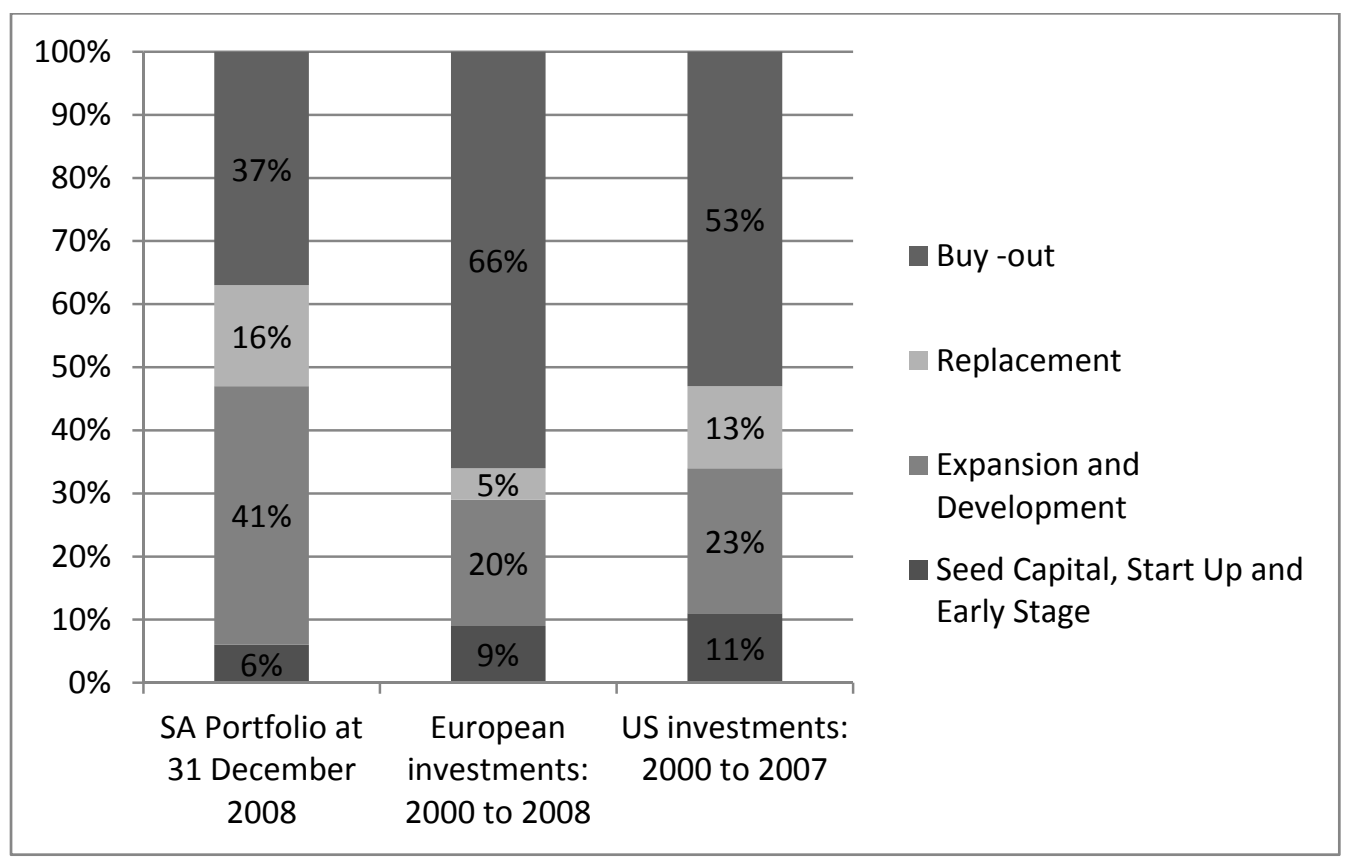

Source: KPMG \& SAVCA 2009

Figure 1: Analysis of investments by stage based on cost of investments - Comparison of South Africa, Europe and the US

IPOs also provide signalling to the market (Black et al., 1998). According to Cumming and Fleming (2002), IPO exits are highest ranked because of the level of information asymmetry between the buyer and the seller and thus only high quality businesses would use this route. In many markets, available exit routes are limited to trade sales, and this is sub-optimal to the development of the VC market. Farag et al. (2004) found that the lack of viable exit routes, other than trade sales, had a negative effect on the development of the VC sector in Central and Eastern Europe. Similar results were found by Da Rin, Nicodana and Sembenelli (2006) in a study of 14 European countries and by Banerjee (2008) in the case of India. Both studies found that the stock market has a positive, large effect on VC activity. However, Jeng \& Wells (2000), in a sample of 21 countries, found that the availability of IPO exit routes is a significant determinant of later stage funding decisions but not of funding decisions at the early-stage.

Jeng \& Wells (2000) discussed the potential for emerging market companies to find suitable listing opportunities overseas. They pointed out that the development of NASDAQ in the US and AIM in London offers suitable listing opportunities for small, high growth companies. The regulations and approach of these two stock exchanges incline them to early-stage companies, particularly high tech offerings, benefitting from a large, well-educated investor pool. Using overseas stock exchanges as exit options may appear too remote and potentially risky for $\mathrm{VC}$ funds in South Africa in addition to the issues raised by exchange controls. The Alt-X, which was established in South Africa to attract early-stage companies, is still limited in its ability to create a sufficiently deep investor pool (SAVCA, 2008). The lack of an active or viable IPO exit route makes stock market-based valuations of a business difficult, especially using cash flow valuation techniques (Cumming et al., 2002) since these require establishing the cost of equity and hence an appropriate discount rate. 


\section{Monitoring, labour market rigidities and industry specialisations}

VCs seeking to enter into early-stage investments would assess three forms of risks, namely, internal, external and execution risks as defined by Kaplan and Stromberg (2004). The ability to assess and reflect these risks accurately in contracts, covenants and in decision making is critical (Van Deventer \& Mlambo., 2009). Post-investment, VC funds require significant commitment of resources in terms of investor management involvement and monitoring so as to add value and to ensure that investee companies are growing appropriately (Gilson, 2003). The clustering of VC firms around key technology and growth company hubs helps to alleviate the monitoring problem as is the case in the US (Kenney et al., 2002) and in India (Dossani et al., 2002). In South Africa, the concentration of the financial community in Johannesburg, might present a problem for entrepreneurial development outside Gauteng.

VC focus, for example in the US and Israel, also tends to be on high tech industries, particularly information and bio technology (Dossani \& Kenney, 2002). This may also result in the concentration of expertise in only a few industries. However, in India, other investable industries include software, pharmaceuticals, agriculture and industries allied to these (Dossani \& Kenney, 2002).

Labour market rigidities and regulations also impact the level of innovation, entrepreneurship and early-stage VC investments (Sahlman, 1990; Jeng \& Wells, 2000; Da Rin et al., 2006). In South Africa, there are a number of employment-linked regulations in force. These include the Broad-Based Black Economic Empowerment (BBBEE) or Employment Equity (EE) (Lingelbach et al., 2009), which may need to be considered in entrepreneurial and investment decisions.

\section{The role of government}

The government plays a critical role in establishing the $\mathrm{VC}$ sector and in developing early-stage VC funds (SAVCA, 2008). The government can do this through the implementation of sound monetary and fiscal policies that largely establish and maintain a stable macroeconomic environment (Dossani \& Kenney, 2002; Kenney et al., 2002). Favourable taxation policies on risky investments would enable high returns and thus encourage new earlystage investments (Da Rin et al., 2006). Lower capital gains taxes (CGT) enable greater returns to be captured by investors and the difference between the income tax and the CGT would lower the potential cost of leaving one's job and becoming an entrepreneur (Da Rin et al., 2006).

The US VC market benefited significantly from policies that support the funding of University research and providing a ready supply of well-trained graduates, from science and engineering backgrounds (Dossani \& Kenney, 2002; Kenney et al., 2002). The Massachusetts Institute of Technology (MIT), Stanford, California and Berkeley universities played a particularly important role in developing VC funds in the US (Kenney \& Von Burg, 1999). The US has been successfully spinning off research and innovation (Bottazzi \& Da Rin, 2002) and other governments around the world have tried to replicate (Megginson, 2004) with varying degrees of success.

In the US, the Employment Retirement Income Security Act (ERISA) of 1972, which made pension funds criminally liable for losses incurred in high risk investments almost destroyed the VC sector when pension funds stopped investing in VC (Dossani \& Kenney, 2002). It took 9 years of intensive lobbying by the National Venture Capital Association to have the restrictions finally removed (Dossani \& Kenney, 2002). What is required is the establishment of legislation that encourage the formation of VC firms that can successfully attract and contract out risk, while protecting investors (Cumming \& Fleming, 2002). Equally important is a legal framework that is strong in providing legal protection and rights to investors and entrepreneurs (Karsai et al., 1997; and Cumming \& Fleming, 2002).

Whilst the US government played no direct role in the establishment of the US VC industry (Gilson, 2003), many governments around the world have attempted to engineer and support this industry. The German government, for example, formed the Deutsche Wagnisfinanzierungsgesellschaft (WFG) in 1975, using capital to the value of 50 million Deutschemarks provided by 29 German banks and with 75 per cent of WFG's losses guaranteed by the government. The WFG's mandate was to provide VC funding to entrepreneurial businesses with the explicit goal of enhancing innovation creation and conversion (Becker \& Hellman, 2003). The results were fairly disastrous in that more than two thirds of WFG's portfolio companies resulted in partial or total losses, and less than 20\% ever generated any returns (Becker \& Hellman, 2003). The combined internal rate of return of WFG's portfolio over its lifetime was estimated to be a negative 25 per cent (Gilson, 2003).

In contrast, in Israel, government policies are generally considered to have "supercharged the growth of the Venture Capital" industry (Dossani \& Kenney, 2002: 12). Key to this was the establishment of Yozma, a government-funded organisation meant to encourage $\mathrm{VC}$ in Israel. Yozma created nine $\mathrm{VC}$ funds, in which it invested alongside the private sector (Gilson, 2003). The role of Yozma and its operations, including the nature of guarantees and call options, were different from those of the WFG. Whereas investment decisions were made by the board in the case of the WFG, fund managers made the investment decisions in the case of Yozma and they were appropriately incentivised (Sahlman, 1990). Yozma's investment funds were all largely successful, grew in size and were ultimately privatised. Although one may attribute the success of the Israeli VC market to its strong ties with the US, it is important to note that most VC-backed Israeli companies were also increasingly able to approach the US market as their IPO destination of choice (Avnimelech \& Teubal, 2004). 


\section{Data and methodology}

This research is mostly qualitative, given that the investigation revolves around opinions and personal insights of industry stakeholders. The data was primarily collected through a self-completed online questionnaire to allow a wider geographical spread of the respondents. The questionnaire contained both closed and open-ended questions in order to enable an element of both ranking and personal insight. The use of rankings within the surveys enabled variation between responses to be explicitly identified. Open-ended questions enabled participants to provide greater detail on key issues.

Interviews were then used to supplement the data collected through the self-completed questionnaire. The interviews were typically 45 minutes to one hour long. Each interview was recorded, but detailed handwritten notes of the key issues identified during the interview were also taken. These notes were then supplemented by working through the recordings, picking up where key themes arose or new information was provided. The interview data was used to provide additional detail in relevant areas. This is known as data triangulation which is common in cross-sectional designs (Easterby-Smith, Thorpe \& Lowe, 1991). Triangulation has the advantage of counterbalancing the strengths and weaknesses of the different methodologies used (Abrahamson, 1983).

In sampling potential respondents, the SAVCA database was consulted and the members categorised as VC houses providing early-stage funding, current providers of later stage VC funding, PE players who have avoided the earlystage space, mergers \& acquisitions (M\&A) advisors and other intermediaries. In addition to using the SAVCA database in sourcing potential respondents to the survey, an internet search and alternative sources (such as the Silicon Cape) were used to check for additional potential respondents. The aim was to reach the majority of relevant entities operating in the VC industry in South Africa. Typical respondents included VC houses specialising in smaller-sized deals, university representatives responsible for the commercialisation of research and parastatal organisations concerned with promotion of entrepreneurship, hence having a vested interest in VC development, such as the Industrial Development Corporation (IDC) through the relevant Department of Trade and Industry (DTI) bodies.

In interpreting the data collected through the questionnaires and the interviews, care was taken not to impose personal viewpoints to the findings to ensure conformability. The research tried to capture as broad a set of views as possible within the interest groups identified and the results reported represent an amalgamation of these views. Out of the 54 invitations to participate in the survey, 19 responses in total were received by the cut-off date. This represented a response rate of approximately $35 \%$. The majority (i.e. $48 \%$ ) of the respondents were VC fund managers followed by university research coordinators responsible for the commercialisation of research $(21 \%)$ and PE fund managers (16\%), with government institutions, VC advisors/intermediaries and other categories tied at 5\%. The reported findings reflect the views of these respondents.

\section{Research findings}

Consistent with the literature (e.g. Lerner et al., 2005; Sahlman, 1990; Gilson, 2003), all respondents agreed that $\mathrm{VC}$ is important for enhancing innovation and economic growth $(95 \%)$, job creation $(85 \%)$ and social development $(60 \%)$ and that private sector early-stage VC is lacking in South Africa (18 out of 19 respondents). The general feeling was that significant amounts of private sector money are available to venture capitalists, but they are mostly directed at the later stage than at the seed and start-up phases. According to the interviewees, fund managers may claim that they look at "start-up" investments, as many do in their SAVCA profiles, but this is generally not the case. The vast majority of activity is focused on post revenue businesses, typically with at least 2 years of track record, where the product/service is in the market and the business already has customers.

While angels were reported to be a key funding option for early-stage non-university based ventures, it was argued that actively investing angels are few and far between and that they typically invest in businesses within their existing networks. With regards the relationship between angel investors and venture capitalists, about $58 \%$ of respondents thought of it as complementary, while $16 \%$ thought it was competing and $26 \%$ considered it to be neutral. A complementary relationship is important to successfully deal with the early-stage funding gap.

While the literature (Dossani \& Kenney, 2002; Jeng \& Wells, 2000) argues that venture capitalists are likely to be more proactively involved in their investee companies, our findings suggest that angel investors get much more involved than VC funds. Angels tend to attend management meetings more regularly than $\mathrm{VC}$ funds and they proactively reach out to their own networks to aid in activities such as sales and distribution. This is because angels typically invest in sectors that they are in or were successfully operating in and have detailed knowledge of, as well as in developed networks. Thus although funding from angel investors may be limited, they bring more to the business than just financing. 
Table 1: Survey respondents' perceptions about VC in South Africa

\begin{tabular}{|c|c|c|c|c|}
\hline Question: & \multirow[t]{2}{*}{ Obs. } & \multirow[t]{2}{*}{ Yes } & \multirow[t]{2}{*}{ No } & \multirow{2}{*}{ Unsure } \\
\hline 1. Is early-stage investing important for: & & & & \\
\hline - Enhanced innovation? & 19 & $100 \%$ & $0 \%$ & $0 \%$ \\
\hline - Economic growth? & 19 & $95 \%$ & $5 \%$ & $0 \%$ \\
\hline - Job creation? & 19 & $85 \%$ & $10 \%$ & $5 \%$ \\
\hline - $\quad$ Social development? & 19 & $58 \%$ & $10 \%$ & $32 \%$ \\
\hline 2. Is there a shortage of private sector early-stage VC in South Africa? & 19 & $95 \%$ & $5 \%$ & $0 \%$ \\
\hline 3. Are IPOs a viable exit option? & 19 & $26 \%$ & $74 \%$ & $0 \%$ \\
\hline 4. Are overseas listing destinations an option? & 19 & $32 \%$ & $47 \%$ & $21 \%$ \\
\hline 5. Does venture capital need geographic clusters? & 19 & $53 \%$ & $47 \%$ & $0 \%$ \\
\hline 6. Are industry specialisations needed? & 19 & $88 \%$ & $12 \%$ & $0 \%$ \\
\hline Question: & Obs. & Complementary & Competing & Neutral \\
\hline 7. The relationship between angel investors and early-stage VC is & 19 & $58 \%$ & $16 \%$ & $26 \%$ \\
\hline 8. The relationship between government and private sector funds is & 19 & $26 \%$ & $32 \%$ & $42 \%$ \\
\hline
\end{tabular}

\section{Key issues facing early-stage venture capital in South Africa}

With regards to the main thrust of the research, possible explanations were given as to why there are so few $\mathrm{VCs}$ looking at early-stage investments in South Africa. First, there are more than enough opportunities at the later-stage with a lot less risk. Secondly, fund managers at present are simply not interested in making small investments since this translate to small returns in absolute terms. Most VCs in South Africa are currently looking at a minimum equity cheque size of R5 million and upwards, which, for a $25 \%$ stake, implies business valuations of at least R20 million.

In rating 14 different factors identified in the literature as impacting early-stage $\mathrm{VC}$ on a scale of 1 (not important) to 5 (very important), respondents identified the ability to raise funds from investors targeted at early-stage investments, a lack of specialised early-stage fund managers and entrepreneurial skill sets to be the top three issues.

\section{Raising funds}

The issue of raising funds was ranked most highly with an average score of 4.4. What was most readily identified was the need to lower the cost of capital in order to enable suitable returns to be made. However, the high cost of capital is commensurate with the high probability of business failure at this stage of development. Generally, according to respondents, the lack of a track record or steady stream of success stories for early-stage investments in South Africa deters the ability to attract funds at the earlystage. It thus makes it difficult to convince pension funds and other investors on the merits of investing at this stage as it is considered too risky by many.

It also came up from the interviews that the introduction of the Broad Based Black Economic Empowerment (BBBEE) investments may have compounded the difficulty in raising funds. Essentially, BBBEE investments fall under replacement capital but they have been the focus of many new funds. The drawing of funds away from early-stage investments has been one of the unintended consequences of the BBBEE initiative. However, contrary to the literature suggesting that labour market rigidities negatively impact early-stage VC activity (Sahlman, 1990; Jeng \& Wells, 2000; Da Rin et al., 2006), BBBEE was lowly ranked in this study as a factor impacting early-stage $\mathrm{VC}$ investments in this specific regard.

A further issue raised was the inability to attract early-stage investments from overseas where a significant proportion of PE funds in South Africa come from. Some of the survey and interview participants blamed this on South Africa's inhibitive exchange controls. 


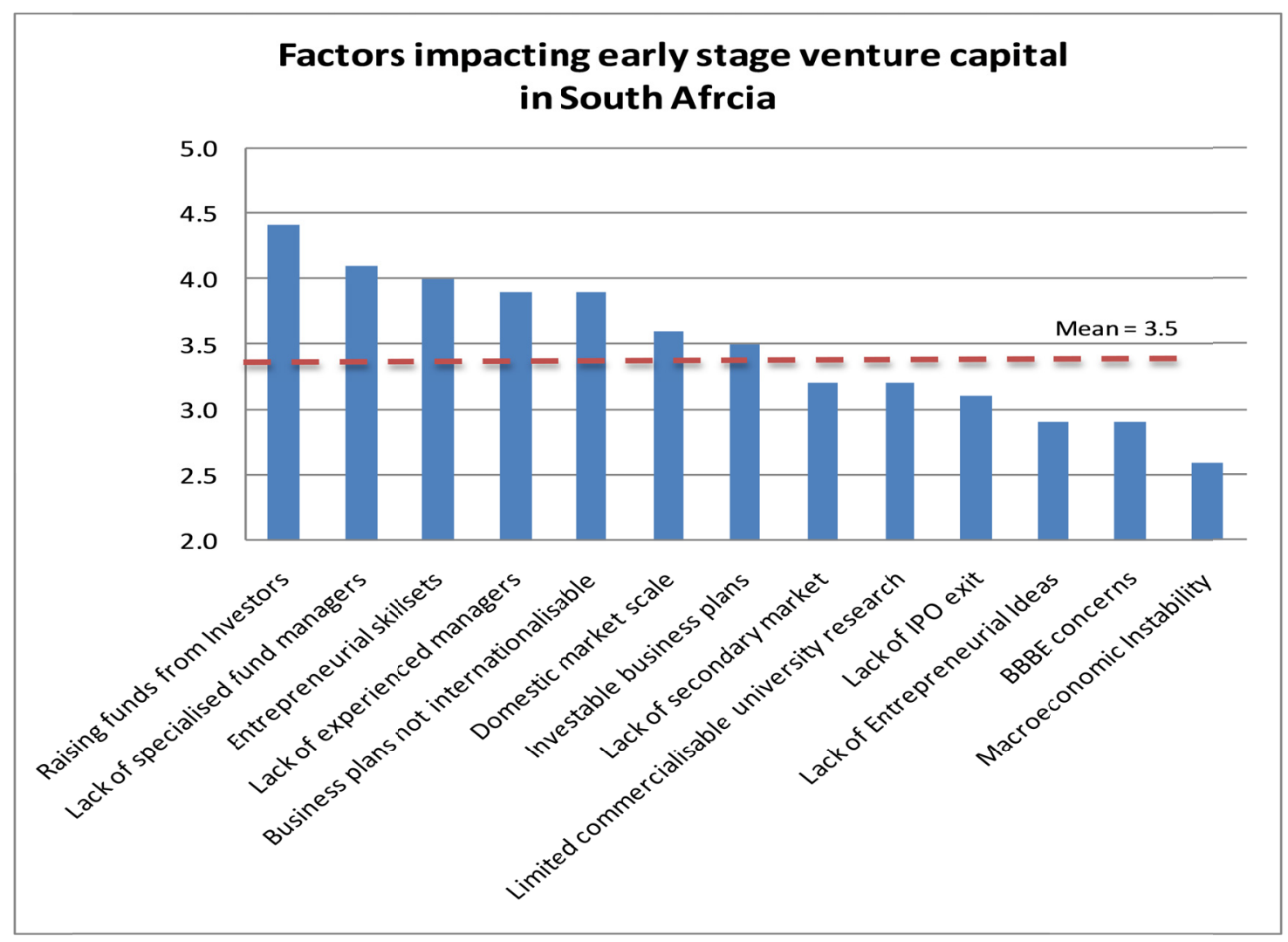

Figure 2: Factors impacting early-stage venture capital in South Africa

\section{Lack of specialised early-stage venture capital fund} managers

The second highest ranked issue was a lack of specialised fund managers at the early-stage. Despite many businesses at the early-stage needing more hands-on help across the board and not just financing, the general sense was that, unlike with angel investors, there is no small-business experience at present at $\mathrm{VC}$ firms to enable VC partnerships to be fulfilling at the early-stage. What is needed is the right pool of managers. According to the literature (e.g. Kaplan \& Stromberg, 2004), funds will typically focus on a specific area because of the need to establish a clear mandate for investors at the time of raising the funds. In addition, the traditional $\mathrm{PE}$ and/or later stage investment criteria, and their holding periods, are not directly transferable to earlystage investments.

\section{Entrepreneurial skill sets}

The third highest ranked issue is the quality of entrepreneurial skill sets. To probe further on this issue, respondents were asked to rank 6 issues concerning entrepreneurship in South Africa in order of importance. The top-ranked issue was given a score of 6 and the lowest a score of 1 .
As can be seen from the average scores plotted in Figure 3, the lack of general business skills was ranked as the number one priority problem area in line with research findings from Central and Eastern Europe (Farag et al., 2004; Karsai et al., 1997). The feeling was that South Africa has plenty of innovative ideas but the inventor is rarely the right person to take it to market. Experienced business managers are required. The networks of business contacts maintained by VCs are neither formal nor available at the necessary scale to help businesses and often come post-investment yet many entrepreneurs need assistance prior to $\mathrm{VC}$ funding and the costs can be prohibitive.

In line with Bliss (1999), it was reported that some entrepreneurs do not understand the nature of $\mathrm{VC}$ funding. In some instances they assume that they are being given a loan and are, therefore, reluctant to give up significant equity stakes. They also tend to use overinflated valuations in their business plans, based on unproven concepts being taken to multiple country markets. This often leads to many difficult discussions when they approach venture capitalists for funding, especially with regards to early-stage investments where actual outciomes are uncertain. 


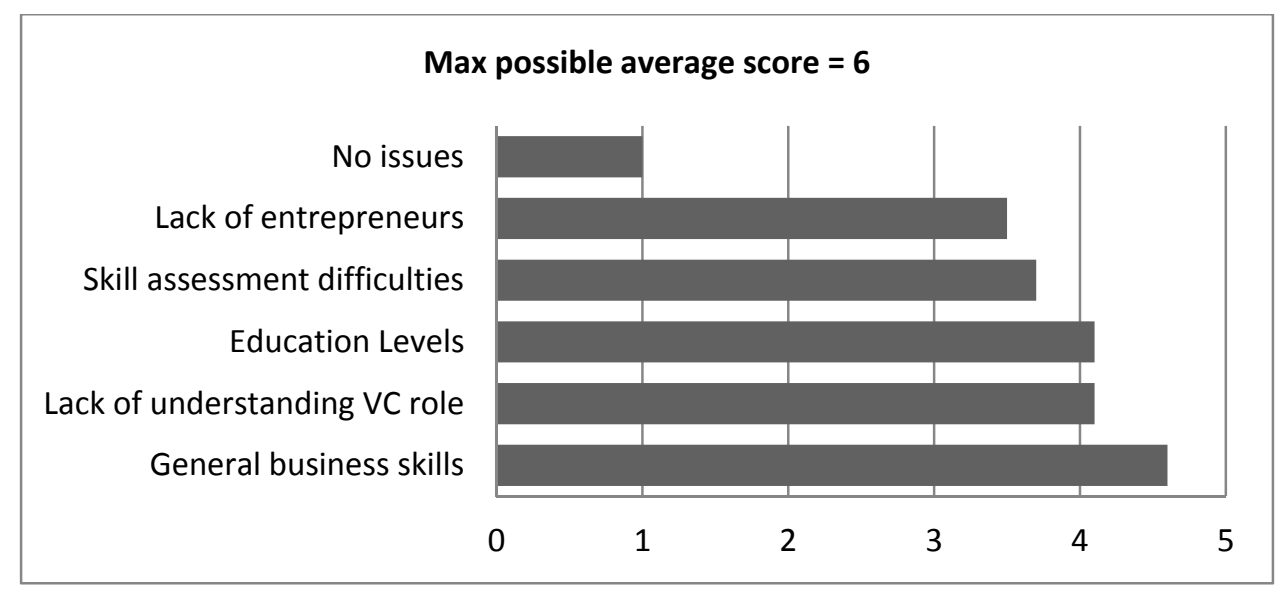

Figure 3: Key issues relating to entrepreneurship in South Africa

Other highly ranked issues regarding entrepreneurship include the education levels in South Africa, difficulties in assessing skills and the lack of entrepreneurs in general. The general feeling from the interviewees was that inventions coming from universities are of relatively higher quality than non-university inventions. However, there is a lack of track record of successful university-sourced business plans and inventions. This was blamed on the university models for promotion which encourages publications rather than patent-filing and the commercialisation of research. In some cases the value of intellectual property (IP) is overestimated without enough market research.

However, according to university respondents, universities' technologies are often in an early-stage of development and the necessary funds to develop such technologies to a stage where VCs are willing to invest are usually not forthcoming. Some university research can be very expensive requiring millions of rand to be invested even before the concept is market-proven. Such research is unlikely to be backed by VCs and the short-time horizons that VCs are looking to invest are incompatible with the commercialisation of university research. There is an attempt by government to fill this gap, for example through the National Research Foundation (NRF), the Innovation Fund, the BRICS ${ }^{3}$ (in respect of biotechnology) and the IDC. ${ }^{4}$

Various university technology transfer offices lobby government through the South African Research \& Innovation Management Association (SARIMA). The focus has, however, shifted in recent years away from technology transfer and SARIMA towards general research and the NRF. While the interaction between the technology transfer

\footnotetext{
${ }^{3}$ Brazil, Russia, India, China and South Africa.

4 The Innovation Fund was, however, criticised in that it requires the intellectual property (IP) to be kept within the country reducing the ability to internationalise the business. Although the IDC was acknowledged as important and much better able to work within this space, given its new internal structure and VC fund, its fund size and the scale of its operations were questioned in terms of addressing such a large and important market across South Africa. The bulk of research funded by the NRF is general and not pro-commercialisation.
}

offices of the various universities is being addressed with greater cooperation and coordination, a forum for formal discussions with SAVCA, SARIMA and the broader PE/VC community could enhance understanding between the different parties.

\section{The importance of IPOs as an exit route}

Contrary to the literature (e.g. Jeng \& Wells, 2000; Da Rin et al., 2006), it was reported by $74 \%$ of the respondents that the lack of an IPO exit route does not impact investment decisions in South Africa. The Alt-X is not seen as a viable option and very few, if any, VC funds have successfully listed on this market. Exit routes of choice seem to be trade sales and secondary sales to later stage investors. Despite the importance and profile of other listing destinations such as AIM and the NASDAQ, and the literature's support of these as alternative exit routes for VCs in emerging markets (Da Rin et al., 2006), about $47 \%$ of the respondents felt that overseas listing destinations were not an option whilst $21 \%$ were unsure.

\section{Geography and industry specialisations}

Although $53 \%$ of the respondents said VC activity needs to be clustered geographically, monitoring from a distance was not perceived to present problems, especially for particular industries such as Information and Communication Technology (ICT) where businesses are much more virtual and hence accessible. However, the importance of networking initiatives such as the Silicon Cape, which brings together people from all over South Africa and internationally, was acknowledged. 


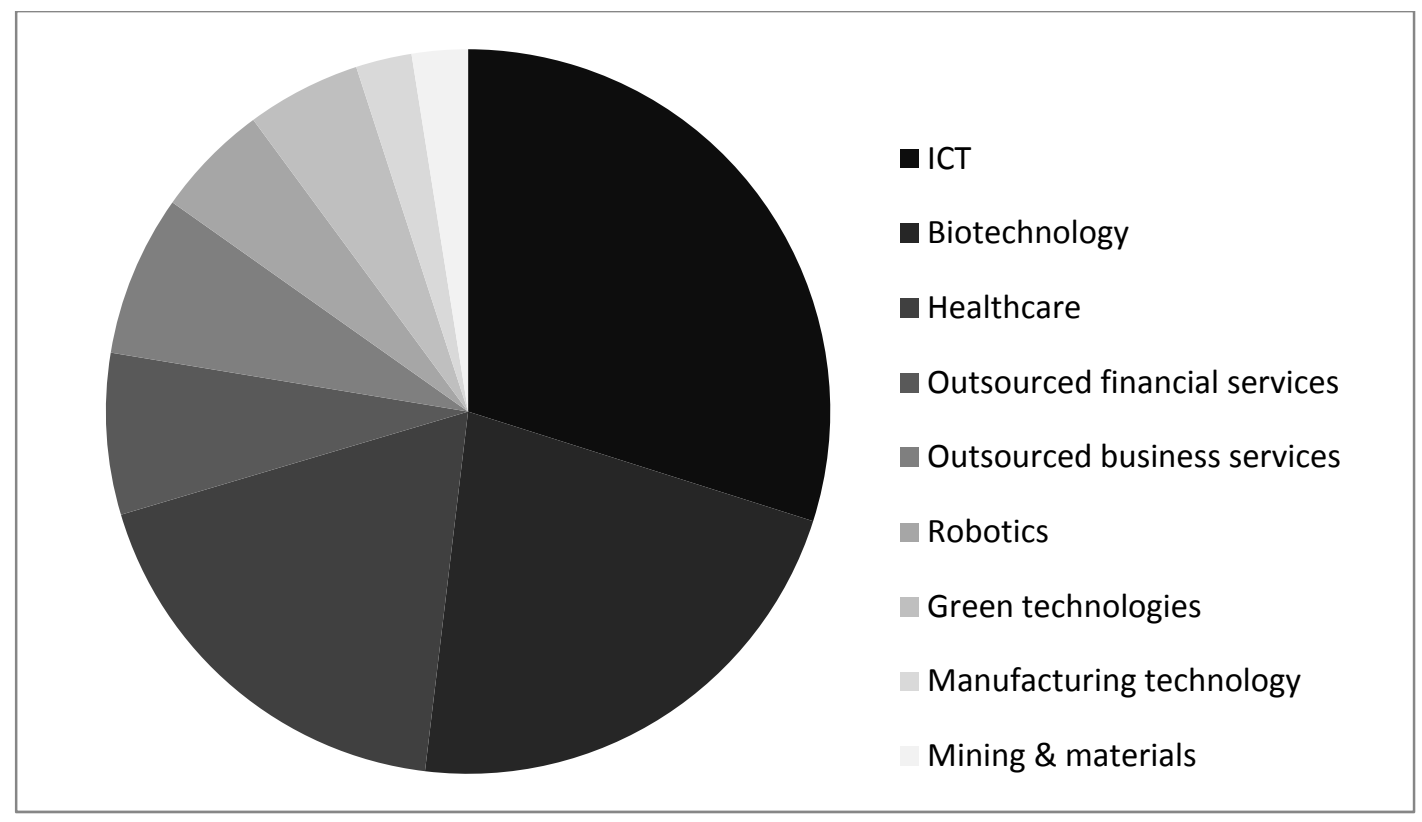

Figure 4: Industry specialisations that are likely to emerge in South Africa

Industry specialisations were considered important by $88 \%$ of the respondents. It was suggested that infrastructure and networks should be focused around industries such as ICT, Biotechnology and Healthcare (see Figure 4). According to respondents, if South Africa can develop solutions to address, for example, the lack of infrastructure and limited broadband access in large townships and rural areas, these could be exported to other emerging economies with similar challenges such as India and China. The respondents cited the importance of mobile and mobile applications as an example in which South Africa could develop and sustain a critical competitive advantage.

\section{The role of government}

The majority of respondents (18 out of 19) indicated that the government is not doing enough to aid early-stage venture capital. As for the relationship between quasi-government funds and private sector $\mathrm{VC}, 42 \%$ of the respondents thought of the relationship as neutral while $32 \%$ thought of it as competing and only $26 \%$ thought of it as complementary. The respondents considered tax incentives to be the number one priority area for government action, followed by government funding to the $\mathrm{VC}$ sector (see Figure 5).

\section{Tax incentives}

In line with the literature (e.g. Da Rin et al., 2006), the need for tax incentives was not only the highest ranked, but was repeatedly brought up in the interviews and the issue raised by the Silicon Cape and the media (Engelbracht, 2009). It also remains an important topic in other developed $\mathrm{VC}$ markets such as the US (Aberman, 2009). Lack of tax incentives can explain the inability of funds to attract investments from overseas and locally, and the lack of success by universities in raising funds from alumni.

\section{Government funding}

With regards to government funding, it was felt that the level of funding was simply not enough. Some also felt that certain government funds are specifically seeking to take equity stakes in existing businesses rather than aiding the creation of go-to-market products and services at stages that are too early for VCs. Such direct involvement by government may end up "crowding out" private sector VC investments. A similar issue was that of government agencies acting as real partners just like private sector VCs views their role. However, a lack of the necessary skill sets, experience or empowerment on the part of these managers to take key funding and business decisions when working with investee companies often lead to unhelpful and unnecessary delays. It was suggested in one interview that when a VC work alongside government, the issue of decision-making can be resolved through the $\mathrm{VC}$ acting as a proxy for voting shareholders.

The many different government funds and a lack of transparency and understanding as to which body has what mandate was also considered an issue, thus making the future role of the Technology Innovation Agency (TIA) as a coordinating body important. 


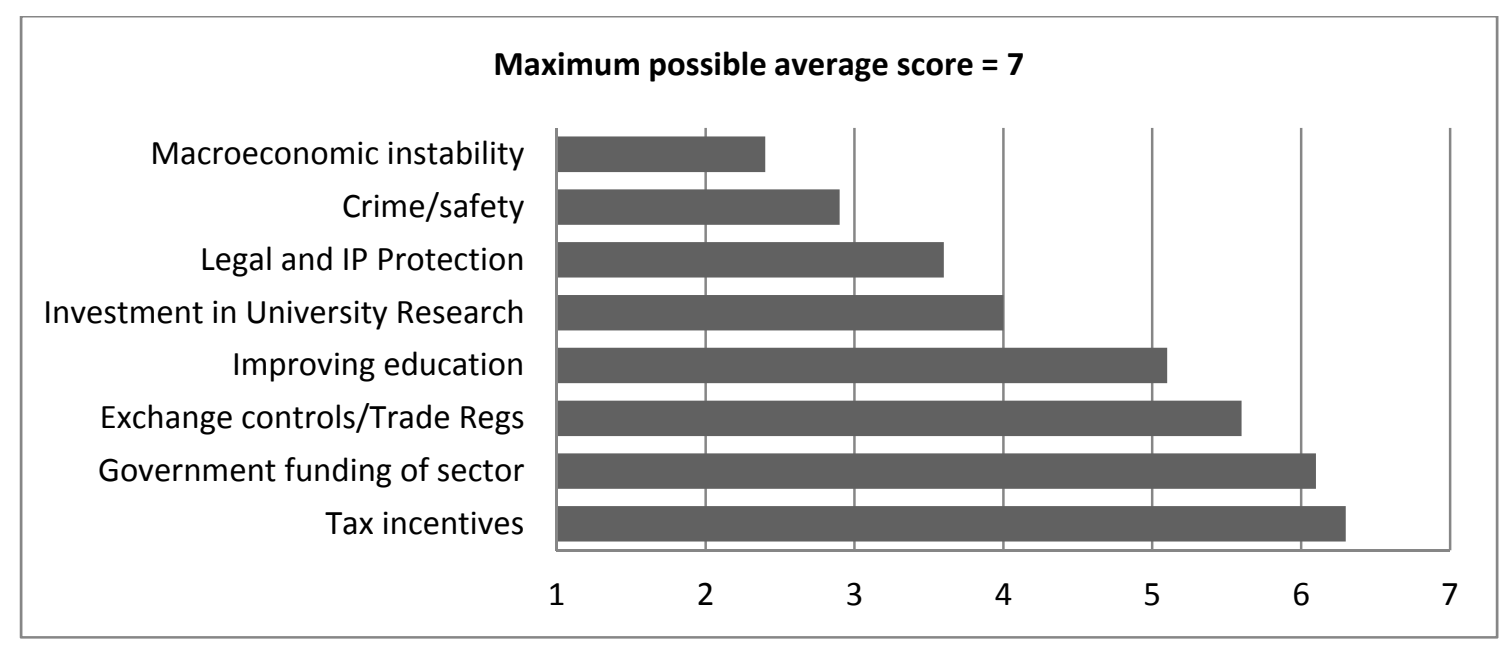

Figure 5: Key issues for government attention

\section{Exchange controls and trade regulations}

Exchange controls and trade regulations have been highlighted often by market participants and by SAVCA (2008) as presenting barriers to the internationalisation of IP and for South African businesses that want to sell abroad especially with regards to payments. The current IP legislation was considered too restrictive and the government was critiqued for not consulting widely enough with universities and VCs in drawing up the legislation. The general feeling was that the domestic market is simply not big enough to offer the real potential that taking a business internationally brings. It was also argued that although almost all decent exits are effectively done offshore, the new legislation prevents this. It was revealed that the process of approval by the Reserve Bank can be frustratingly long with some approvals taking up to 18 months.

\section{Measures that can be taken to promote early-stage VC funding in South Africa}

With regards to raising funds, it was recommended in the interviews that an "angel fund" be created into which high net worth individuals can contribute funds without taking away the opportunity for them to get directly involved in the running of the business. The fund could have a general/limited partnership structure, just like a typical VC/PE fund, with a management team to manage funding applications, deal transactions and for administration. The fund would benefit from a pool of experienced businessmen, either focused on particular industries thus creating industryspecific funds, e.g. a tech fund or a healthcare fund, or interested in investing generally, either way maximising the breadth and scale of mutual networks and contacts. In addition, potential investments could be debated amongst angels thus offering a greater level of due diligence for the investment.

In response to the lack of specialised early-stage fund managers, the respondents alluded to the fact that more successful entrepreneurs need to be directly involved in setting up their own funds. It was also highlighted that universities can establish their own $\mathrm{VC}$ fund to target university inventions which are considered to be of a significantly higher quality than non-university inventions, thus offering a completely different risk profile for investors.

To address the lack of entrepreneurial skill sets, the respondents pointed out the need to find ways to formalise the VC-business networks in order to tap into the skills available in South Africa through mentorships, and possibly through incubators. The government's role could be to direct funding into the "incubation of start-up businesses, mentoring \& coaching of new entrepreneurs and for provision of business support to start-up companies during the first years of their lives." (Interviewee)

Many respondents also pointed to the need to alter learning at schools and universities to encapsulate business management and other skills likely to aid entrepreneurs. For example, Science, Technology and Business Skills could be made compulsory at school, and lessons could be learnt from China, South Korea, Ireland and other growing economies with regards to their education systems (Interviewee). The respondents also called for a shift in the entrepreneurial culture in South Africa so that failure and learning can be better accepted.

It was argued that universities can help educate inventors with regards to creating realistic and investable business plans. One university interviewee indicated that their university has started to employ retired businessmen and professors to scout or survey $\mathrm{PhD}$ work being done to find what might have the potential for realistic commercial applications and providing this perspective to those undertaking the research.

Where government is concerned, the respondents suggested that legislation regarding tax incentives needs to be drawn in line with other countries overseas (such as the UK) where such incentives exist. This would significantly contribute to an enabling environment for VC. Respondents also recommended that the government's funding should be done 
through private sector VC. The government should seek to de-risk private sector investments, instead of pursuing the good returns for itself, and should stop "making all sorts of development demands that cannot be met" (Interviewee). This appears to be in-line with the literature (Gilson, 2003; Dossani \& Kenney, 2002) where, in the case of Israel, the government merely provided funds as an anchor investor to a privately managed fund.

\section{Conclusion and recommendations}

This study set out mainly to explore the reasons for the lack of early-stage VC in South Africa and to provide some proposals for its development. First, the survey participants concurred that $\mathrm{VC}$ is a critical mechanism in support of innovation and economic growth. It was established, however, that although South Africa has a later stage VC market and a well-developed PE market, there are very few early-stage VC funds available, whether private or government funded. This presents a problem for entrepreneurs seeking capital at the early-stage as they are faced with a limited set of funding options. This lack of early-stage VC in South Africa is attributed to the difficulty in raising funds targeted at early-stage investments followed by the lack of experienced managers to help entrepreneurs through mentoring and incubation. The latter is critical given the low level of entrepreneurial skill sets in the country, with entrepreneurship more opportunistic than visionary or game-changing.

Angel investors are seen as complementary to early-stage VC, particularly in providing smaller investments. However, the absence of a formal structure to pool funds from angels presents a potentially missed opportunity. It is recommended that the role of angel investors be formalised and that the latent pools of financial capital and business skills available in the country be tapped into. Tax incentives can be used to encourage a more formal pooling of funds from angels whilst maintaining their involvement in accessing networks and as mentors.

Contrary to the literature (e.g. Da Rin et al., 2006; Jeng \& Wells, 2000), the lack of a realistic IPO exit route does not appear to impact early-stage VC in South Africa. Some respondents claimed that AltX has not yet been used as an exit route for most VC investments. However, research that explores how stock exchanges such as AIM and NASDAQ built their critical masses is important for the AltX to draw lessons from so that it can perform its role effectively.

There was a general feeling that cooperation, communication and understanding between universities, VCs and the government in South Africa are limited. This is seen to impact the degree to which university research can be commercialised. Some suggested that the government should revisit its funding approach to the $\mathrm{VC}$ sector, and should increasingly be involved in developing business skills and incubators for entrepreneurs. With respect to coordinating efforts, SAVCA was seen to be more appropriate for this role, in addition to publicising the $\mathrm{VC}$ success stories to build awareness and understanding of the sector. Lessons can also be drawn from other markets where such success stories exist.

The small sample size used for this research was unavoidable given the limited number of VC firms in South Africa. Nevertheless, the triangulation method used, and resorting to descriptive methods of analysis, made our findings relatively robust. Future research, however, should try to find ways of increasing the sample size in order to avoid the small sample bias, especially when statistical methods of analysis are to be used.

\section{Acknowledgement and disclaimer:}

The development of this work for publication was supported by the National Research Foundation (NRF). Any opinion, findings and conclusions or recommendations expressed in this material are those of the authors and not of the NRF or the authors' respective institutions. Neither the NRF nor the authors' respective institutions accept any liability in this regard thereto. We also acknowledge the useful comments from two anonymous referees. Any errors and omissions remain ours

\section{References}

Aberman, J. 2009. The decline of the United States venture capital industry: What the federal government should do about it. Washington, D.C.: Amplifier Ventures.

Abrahamson, M. 1983. Social research methods. Englewood Cliffs, NJ: Prentice Hall.

Avnimelech, G. \& Teubal, M. 2004. 'Venture capital startup co-evolution and the emergence $\&$ development of Israel's new high tech cluster', Economics of Innovation \& New Technology, 13(1): 33-60.

Banerjee, A. 2008. 'Private equity in developing nations', Journal of Asset Management, 9(2): 158-170.

Becker, R. \& Hellman, T. 2003. 'The genesis of venture capital: Lessons from the German experience', CESifo Working Paper No. 883, Sauder School of Business.

Black, B. \& Gilson, R. 1998. 'Venture capital and the structure of capital markets: banks versus stock markets', Journal of Financial Economics, 47(3): 243-277.

Bliss, R. 1999. 'A venture capital model for transitioning economies: The case of Poland', Venture Capital: An International Journal of Entrepreneurial Finance, 1(3): 241-257.

Bottazzi, L. \& Da Rin, M. 2002. 'Venture capital in Europe and the financing of innovative companies', Economic Policy, 17(34): 229-270. 
Cumming, D. \& Fleming, G. 2002. 'A law and finance analysis of venture capital exits in emerging markets', Working Paper Series in Finance 02-03. Canberra: The Australian National University.

Da Rin, M., Nicodana, G. \& Sembenelli, A. 2006. 'Public policy and the creation of active venture capital markets', Journal of Public Economics, 90(8-9): 1699-1723.

Dossani, R. \& Kenney, M., 2002. 'Creating an environment for venture capital in India', World Development, 30(2): 227-253.

Easterby-Smith, M., Thorpe, R. \& Lowe, A. 1991. Management research: An introduction. London: SAGE Publications Ltd.

Engelbracht, C. 2009. 'Give angel investors tax relief to plug fund gap of start-ups', Business Report, November 26, 2009. [Online] URL: http://www.aurik.co.za/give-angelinvestors-tax-relief/

Farag, H., Hommel, U., Witt, P. \& Wright, M. 2004. 'Contracting, monitoring, and exiting venture investments in transitioning economies: A comparative analysis of Eastern European and German markets', Venture Capital: An International Journal of Entrepreneurial Finance, 6(4): 257-282.

Gilson, R. 2003. 'Engineering a venture capital market: lessons from the American experience', Stanford Law Review, 55(4): 1067-1103.

Gompers, P., 1994. 'The rise and fall of venture capital', Business and Economic History, 3(2): 1-26.

Gompers, P. 1995. 'Optimal investment, monitoring, and the staging of venture capital', The Journal of Finance, 50(5): 1461-1489.

Gompers, P. \& Lerner, J. 1999. The venture capital cycle. $2^{\text {nd }}$ Edition. Cambridge, Massachussetts: MIT Press.

Jeng, L. \& Wells, P. 2000. 'The determinants of venture capital funding: Evidence across countries', Journal of Corporate Finance, 6(3): 241-289.

Kaplan, S. \& Stromberg, P. 2004. 'Characteristics, contracts and actions: Evidence from venture capitalist analyses', The Journal of Finance, 59(5): 2177-2210.

Karsai, J., Wright, M. \& Filatotchev, I. 1997. Venture capital in transition economies: The case of Hungary, Entrepreneurship Theory and Practice, 21(4): 93-110.

Kenney, M., Han, K. \& Tanaka, S. 2002. 'Scattering geese: The venture capital industries of East Asia', A Report to the World Bank. BRIE Working Paper 146. Berkeley, California. [Online] URL: http://brie.berkeley.edu/publications/wp146.pdf
Kenney, M. \& Von Burg, U. 1999. 'Technology and path dependence: The divergence between Silicon Valley and Route 128', Industrial and Corporate Change, 8(1): 67-103.

KPMG \& SAVCA. 2009. Venture capital and private equity industry performance survey of South Africa covering the 2008 calender year. Johannesburg: KPMG Services.

Lerner, J., Moore, D. \& Shepherd, S. 2005. 'A study of New Zealand's venture capital market and implications for public policy', A report to the Ministry of Research, Science and Technology, New Zealand.

Lingelbach, D., Murray, G. \& Gilbert, E. 2009. 'The rise and fall of South African venture capital: A coproduction perspective'. [Online] URL: http://papers.ssrn.com/sol3/papers.cfm?abstract_id=1459175

Megginson, W. 2004. 'Towards a global model of venture capital?' Journal of Applied Corporate Finance, 16(1): 826.

Sahlman, W. 1990. 'The structure and governance of venture-capital organizations', Journal of Financial Economics, 27(2): 473-521.

SAVCA. 2008. Venture capital at an inflection point? Johannesburg: SAVCA.

Stillman, R., Sunderland, J., Heyl, L. \& Swart, H. 1999. A venture capital programme for South Africa: study and recommendations. Working paper, Arlington, Virginia: Nathan Associates.

Van Deventer, B. \& Mlambo, C., 2009. 'Factors influencing venture capitalists' project financing decisions in South Africa', South African Journal of Business Management, 40(1): 33-41. 